\title{
A Spreadsheet for Estimating Soil Water Characteristic Curves (SWCC)
}

By Ghada Ellithy

PURPOSE: SWCC can be measured in the lab; however, due to the cost, time, and high variability in the results, empirical equations were developed using multiple regression approaches on databases consisting of a large number of measured SWCCs. The spreadsheet presented herein utilizes different methods that use basic soil properties, such as grain size distribution and Atterberg limits, to calculate the input parameters for van Genuchten and Fredlund and Xing equations. These parameters are required by numerical models, such as SEEP/W, to perform transient seepage analysis. The spreadsheet allows copying the generated curve data points as well as an input into the numerical model. The spreadsheet calculates the SWCCs using seven different methods for comparison. It also compares four closed form models, Gardner (1958), Brooks and Corey (1964), van Genuchten (1980), and Fredlund and Xing (1994), given the model parameters are known.

INTRODUCTION: A steady-state condition for a given seepage scenario indicates that input and output quantities, such as soil hydraulic loading, gradient, and flow rate, remain unchanged with time. When the hydraulic properties of the flow medium and the flow characteristics change with time due to changing of hydraulic boundary conditions, river water level for example, it is referred to as transient flow. Steady-state flow can occur in partially saturated soils, for example, the flow above phreatic surface with constant boundary conditions, as shown in Figure 1.

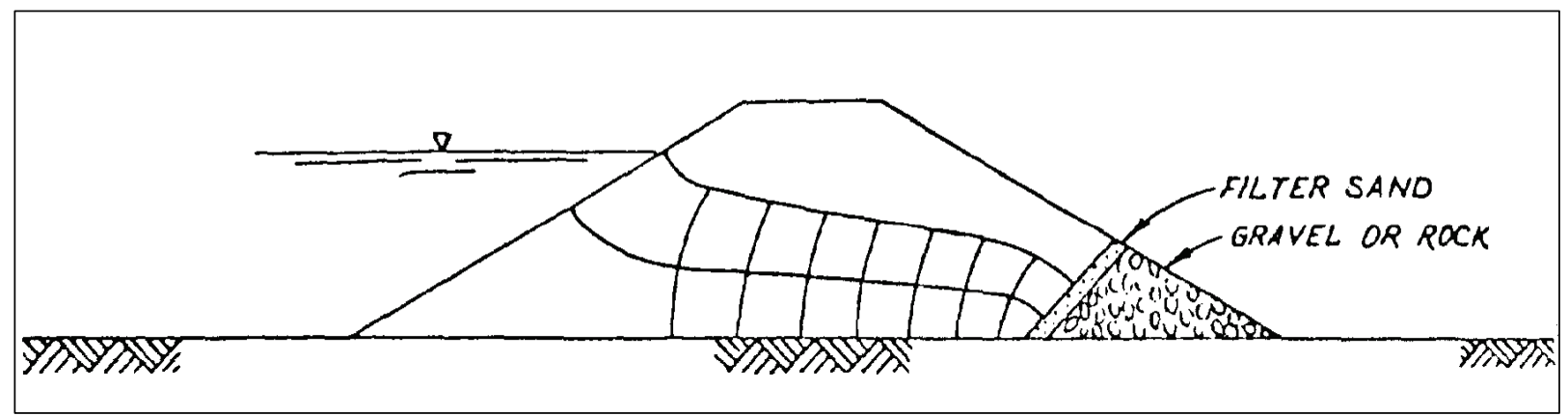

Figure 1. Cross section of unconfined steady-state seepage from EM 1110-2-1901.

Unsaturated flow often refers to flow through soils with negative pore pressures. This can occur in unsaturated soils, where the pores are partially filled with water; however, soil can remain saturated for some distance above the phreatic surface under negative pore pressures. Flow above the phreatic surface through the saturated zone is also considered unsaturated flow.

The assumption that the flow has achieved a steady-state condition is usually conservative from an engineering perspective. Steady-state analyses will normally result in the highest vertical gradients, uplift pressures, flows, and pore pressures that the structures should experience. 
An appropriate use of transient analyses can include: validating the results of piezometer readings during transient flooding events, estimating the time required for steady-state seepage conditions to be achieved, and estimating the development of the uplift forces relative to the hydrograph for the flood event. Tracy et al. (2014) stated that to conduct an accurate transient analysis resulting in reliable output (pore pressures, flows, and hydraulic gradients), the project analyzed would ideally have these characteristics:

- Sandy or non-plastic material as opposed to plastic material such as clayey soils

- Homogeneous soils with well-defined soil properties

- Accurate pre-event hydrograph

- Well-known initial conditions (initial water content and matric suction)

- Well-defined hydraulic boundary conditions (initial and final)

- Previous calibration of pore pressures and gradient to hydrographs and soil properties from installed instrumentation

To perform a transient seepage analysis using modeling programs like SEEP/W (Geo-Slope 2012), it is required to provide the following properties for the modeled soil: the saturated hydraulic conductivity, the soil water characteristic curve (SWCC), the hydraulic conductivity function, and the coefficient of volumetric compressibility, $m_{v}$.

The Soil Water Characteristic Curve (SWCC). The SWCC, also known as volumetric water content function, soil moisture retention curve, and storage function, among other names, describes the constitutive relationship between matric suction $(\psi)$, and the water content of unsaturated soils. The SWCC has been identified as the key soil information required for the analysis of seepage, stability, and volume change problems involving unsaturated soils. Typically, the water content in the SWCC is represented by volumetric water content (VWC or $\theta$ ). In unsaturated soils where the voids are filled with both water and air, the SWCC describes the volume of the voids that remain filled with water as the soil drains.

The matric suction $(\psi)$ in unsaturated soil is the difference between pore air pressure $\left(u_{a}\right)$ and pore water pressure $\left(u_{w}\right)$, Equation 1 .

$$
\psi=u_{a}-u_{w}
$$

The VWC $(\theta)$ is the ratio of water volume to total volume of a soil sample. The VWC is different from the gravimetric water content $(w)$ that is normally used in geotechnical practice, which equals the ratio of the weight of water to the weight of solids in a soil sample. The VWC equals the porosity of the soil sample, when the sample is fully saturated or $S$ is equal to 1.0, Equation 2 .

$$
\theta=n S
$$

where, $n$ is the porosity and $S$ is the degree of saturation. The VWC at full saturation is denoted as $\theta_{s}$. This can still be the case when the soil is under low suction. The SWCC shows a hysteretic behavior depending on whether the soil is draining (desorption) or wetting (adsorption), as shown in Figure 2. Typically, in current analytical tools, one SWCC can be modeled for each soil. 


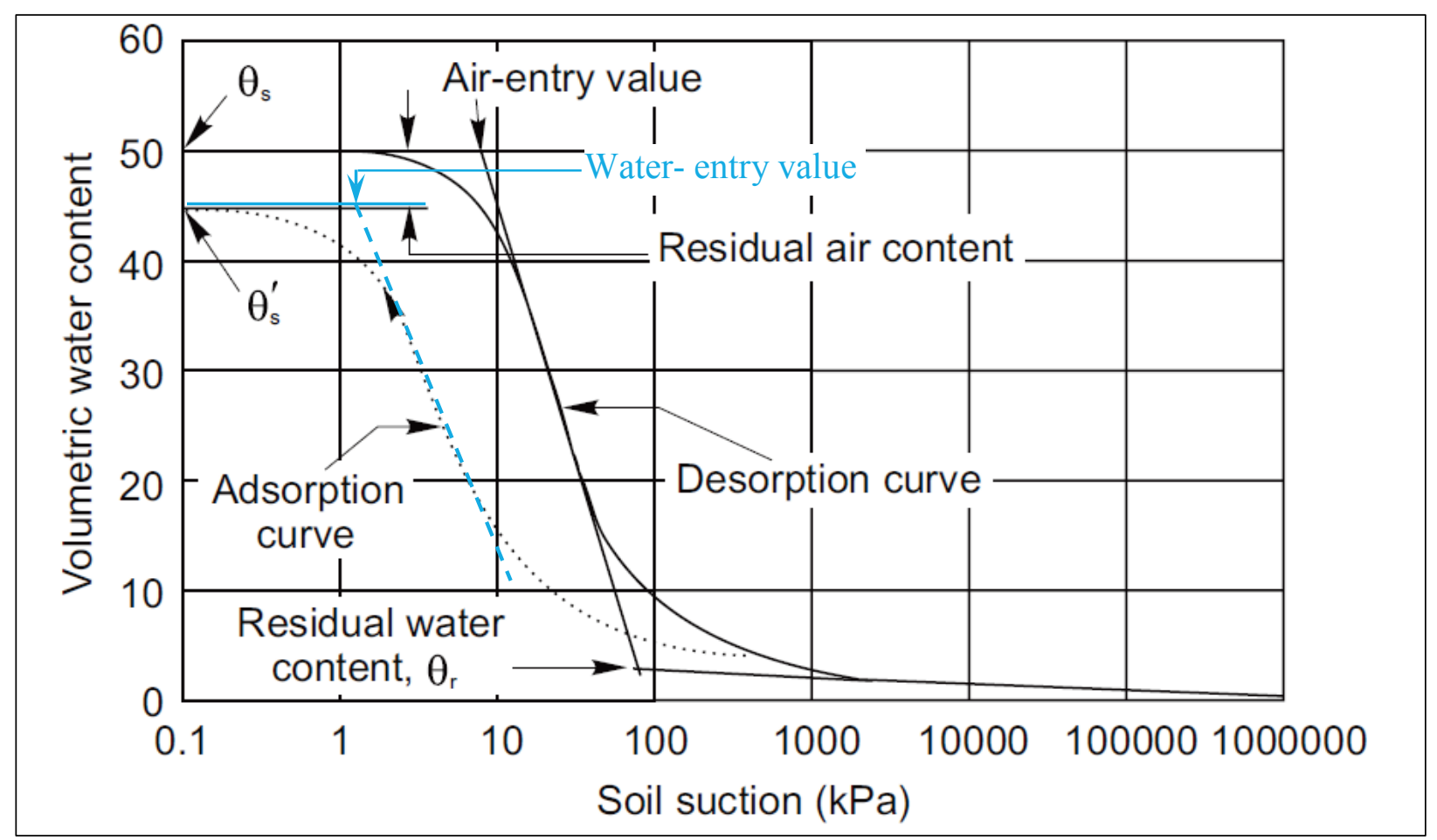

Figure 2. Example SWCC (Fredlund et al. 1994).

Depending on the case being analyzed, either the draining or the wetting curve is selected, or an average curve can be used.

As shown on Figure 2, three main features define the shape of the SWCC (Geo-Slope 2012):

- The air-entry value (AEV), which corresponds to the suction value where the soil begins to drain freely. The AEV, in turn, is influenced by the pore-size distribution within a soil. Soils with large, uniformly shaped pores, like sands, have relatively low AEV, as water can easily be removed under relatively small suction pressures as compared to the high suction values required for silt or clay.

- The residual water content $\left(\theta_{r}\right)$, which is the volumetric water content of the soil where a further increase in suction does not produce significant changes in water content.

- The slope of the quasi-linear portion of the curve, which represents the rate at which the volume of water stored within the soil changes with suction over a range of values from the AEV to the suction corresponding to the residual water content. The uniform nature of the pores in sandy soils causes all pores to drain over a small range of suction pressures, which makes the slope of the SWCC steeper than in finer soils. Figure 3 shows typical water content functions for different soils used in the Geo-Slope's seepage analysis software SEEP/W.

In the following section, it is shown that the models developed to estimate the SWCC have parameters that mainly correspond to the previous three features. 


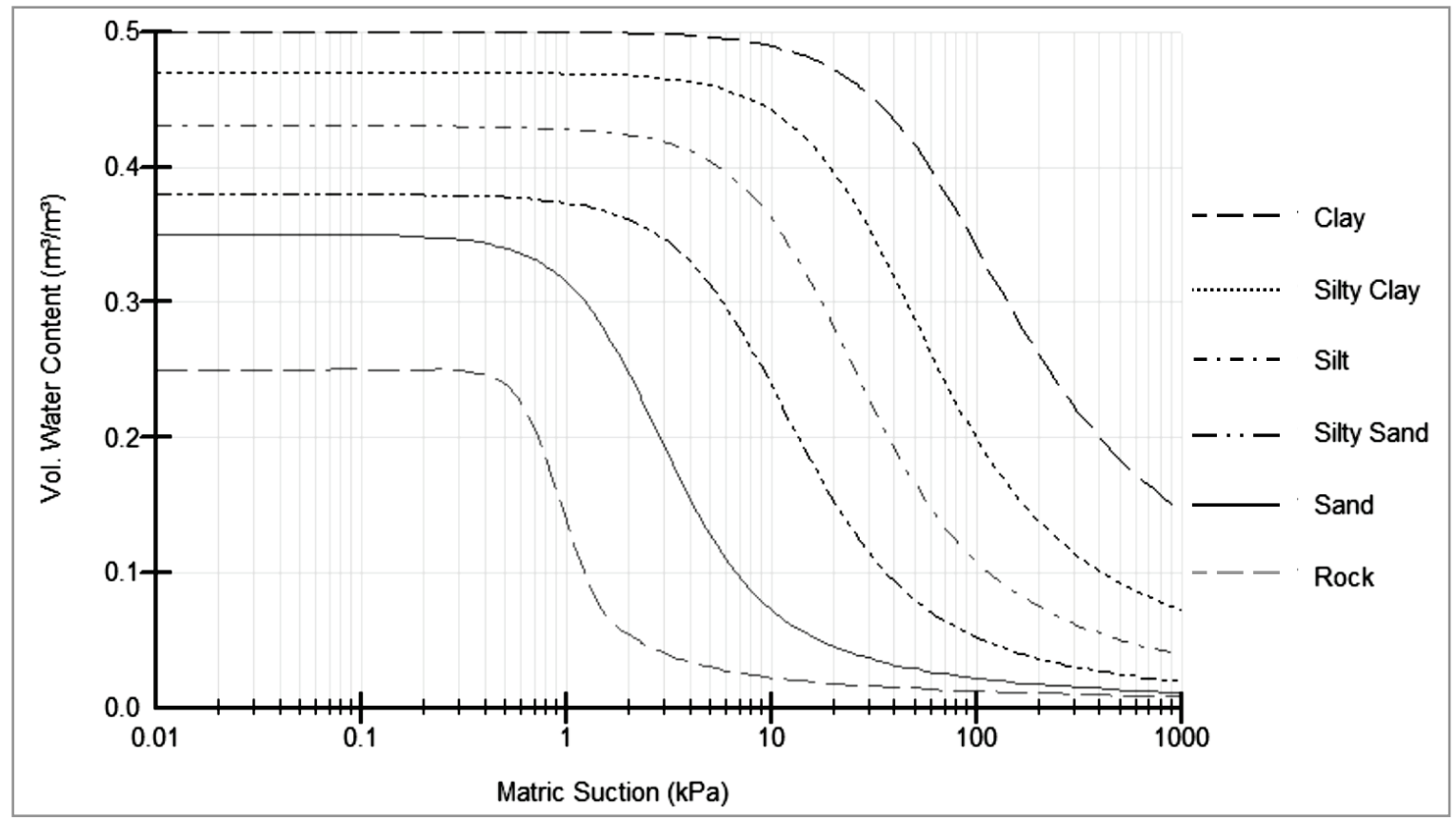

Figure 3. Soil water characteristic curves for different soil types (Geo-Slope 2012).

ESTIMATION OF SWCC: In 1907, Buckingham published the first soil water characteristic curves by plotting the volumetric water content against capillary rise for six soil types varying from sand to clay and analyzed the capillary rise for 53 to 68 days (Figure 4). The experiments were performed on soil columns 48 in. tall and 2.5 in. in diameter and closed on top. The work of Buckingham, as well as the majority of the early work on unsaturated soils, was related to agricultural applications. Over the years, the experimental work and theories were applied to soil mechanics. Currently, unsaturated soil mechanics is well established and accepted amongst geotechnical engineers and researchers; however, as stated by Fredlund and Houston (2001), the use of unsaturated soil mechanics theory into the routine practice is lagging the theoretical development due in large part to the perceived, and often real, difficulties in property determination.

Soil parameters required for modeling unsaturated soils for a particular project can be measured in the lab through a number of testing methods. However, due to the cost, time consuming measurements and uncertainty of results, empirical models were developed over the years to determine the SWCC for different soils. These empirical models can also simplify the determination of other unsaturated soil properties like hydraulic conductivity and shear strength.

Several of these models are in the form of mathematical equations that were fitted to experimental data. Examples of these equations are Gardner (1958), Brooks and Corey (1964), Farrel and Larson (1972), van Genuchten (1980), Williams et al. (1983), and Fredlund and Xing (1994). The mathematical equation models are effective in the sense that they enable an efficient determination of the SWCC from few data points. Also, some of the SWCC applications require that it be in a form of an equation that is differentiated or integrated and continuous (Zapata 2000a). 


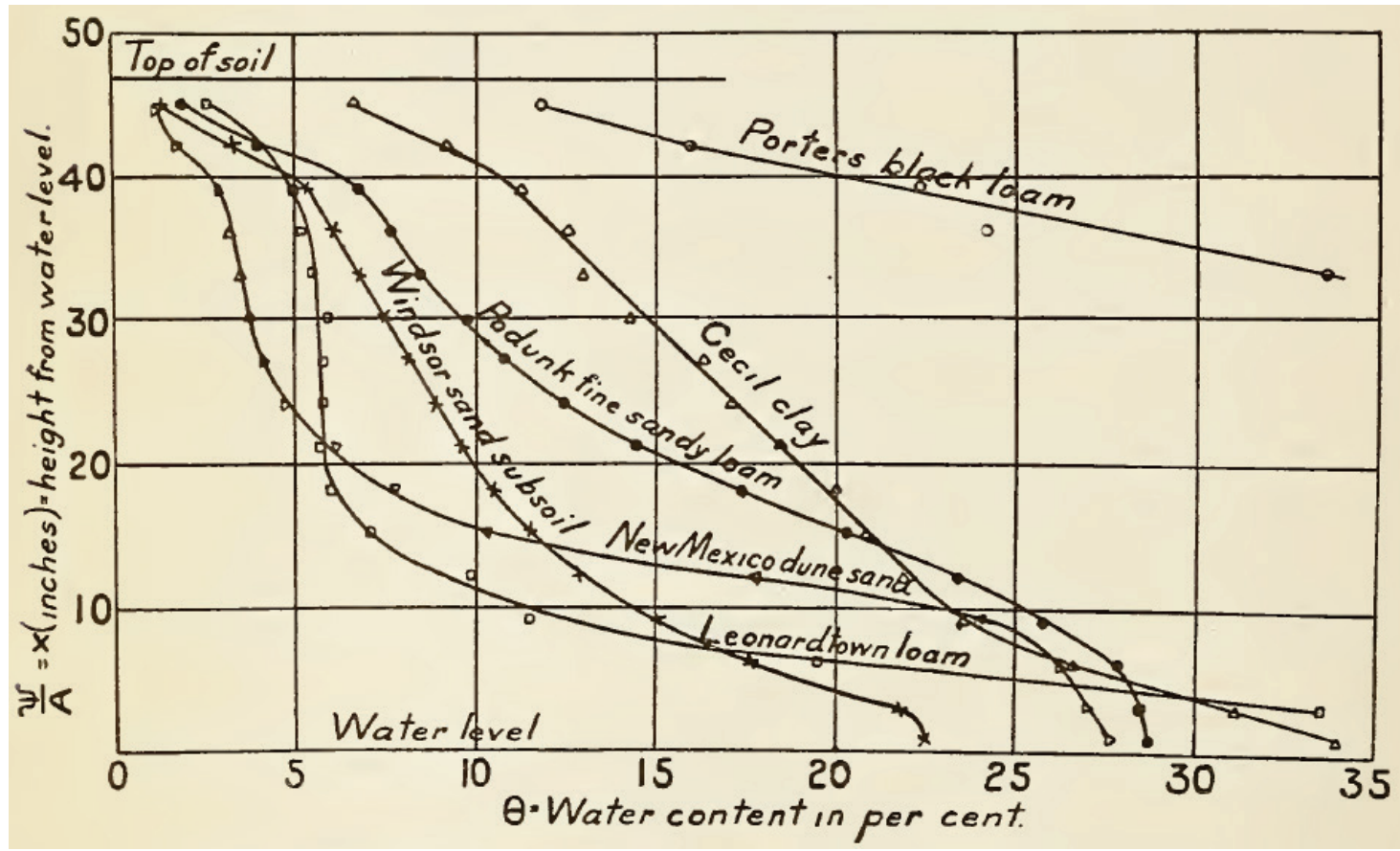

Figure 4. Distribution of water in 48-in columns of soil after 53 to 68 days (Buckingham 1907).

Another type of SWCC models are predictive models. Most of the predictive models are based on multiple regression and statistical approaches. Sleep (2011), Chin et al. (2010), and Johari et al. (2006) classified these models into four major approaches:

- The first is based on statistical estimation of the water content at selected matric suction. The water content then is correlated to soil properties, such as $D_{10}$ and/or porosity. This correlation is a process that requires a regression analysis followed by a curve-fitting procedure. Examples of this approach are Gupta and Larson (1979), Rawls et al. (1982), and Aubertin et al. (2003).

- The second approach uses regression analysis to correlate parameters of a mathematical model, as described in the next section, to soil properties. Examples of this approach are Saxton et al. (1986), Zapata et al. (2000b), and Perera et al. (2005). The quality of the models of the first and second approach rely heavily on the database used to fit and test the equations.

- The third approach uses a physical-based model to predict the SWCC. The physical model involves the conversion of the grain-size distribution into a pore-size distribution curve, which in turn, is related to the distribution of water content and associated pore pressures. This approach was first presented by Arya and Paris (1981), and followed by others, including Fredlund et al. (2002). These models are generally limited to soils with large pores (sands) and to low matric suction ranges.

- The fourth approach uses intelligent algorithm or artificial intelligence methods, such as neural networks, genetic programming, or other machine-learning methods to predict the parameters of analytical equations using available databases of measured SWCCs. Examples of this approach are given by Pachepsky et al. (1996) and Johari et al. (2006). 
To reduce the uncertainty associated with the SWCC estimates arising from both direct measurements and correlation with index properties, a more recent development has been to couple index property-based estimates with a one-point measurement on the SWCC. This measurement can be on an undisturbed sample collected from the field or a compacted sample in the lab. This approach enables shifting the predicted SWCC to pass through the measured data point. Examples of this procedure are presented in Houston et al. (2006) and Chin et al. (2010).

Sleep (2011) proposed a method to estimate the SWCC for course-grained soils using a knowledge-based system. The soils are categorized based on their saturated hydraulic conductivity.

MATHEMATICAL EQUATION MODELS: Leong and Rahardjo (1997) presented a generic form of an equation from which most of the mathematical equation models of the SWCC can be derived:

$$
a_{1} \Theta^{b 1}+a_{2} \exp \left(a_{3} \Theta^{b 1}\right)=a_{4} \psi^{b 2}+a_{5} \exp \left(a_{6} \psi^{b 2}\right)+a_{7}
$$

where, $a_{1}, a_{2}, a_{3}, a_{4}, a_{5}, a_{6}, a_{7}, b_{1}$, and $b_{2}$ are constants, $\psi$ is the matric suction, and $\Theta$ is the normalized volumetric water content:

$$
\Theta=\frac{\theta-\theta_{r}}{\theta_{s}-\theta_{r}}
$$

where, $\theta_{r}$ and $\theta_{s}$ are the residual and saturated volumetric water contents as described earlier. Following are some of the common equations used for modeling SWCCs:

$\underline{\text { Gardner (1958) }}$

$$
\Theta=\frac{1}{1+\left(\frac{\psi}{\alpha}\right)^{n}}
$$

where,

$$
\begin{aligned}
& \alpha=\text { soil parameter dependent on } \mathrm{AEV} \\
& n=\text { soil parameter dependent on the rate of soil drainage }
\end{aligned}
$$

Brooks and Corey (1964)

$$
\Theta=\left(\frac{\psi_{b}}{\psi}\right)^{\lambda}
$$

where,

$$
\psi_{b}=\mathrm{AEV} \text { or bubbling pressure }(\mathrm{kPa})
$$




$$
\lambda=\text { index number of pore size distribution }
$$

van Genuchten (1980)

$$
\Theta=\frac{1}{\left[1+\left(\frac{\psi}{a}\right)^{n}\right]^{m}}
$$

where,

$$
\begin{aligned}
a= & \text { soil parameter dependent on } \mathrm{AEV} \text { or bubbling pressure }(\mathrm{kPa}) \\
n= & \text { soil parameter dependent on the rate of soil drainage } \\
m= & \text { soil parameter dependent on residual water content and can be estimated as } \\
& (m=1-1 / n)
\end{aligned}
$$

Figure 5 shows the effect of van Genuchten's equation parameters on the shape of the SWCC.

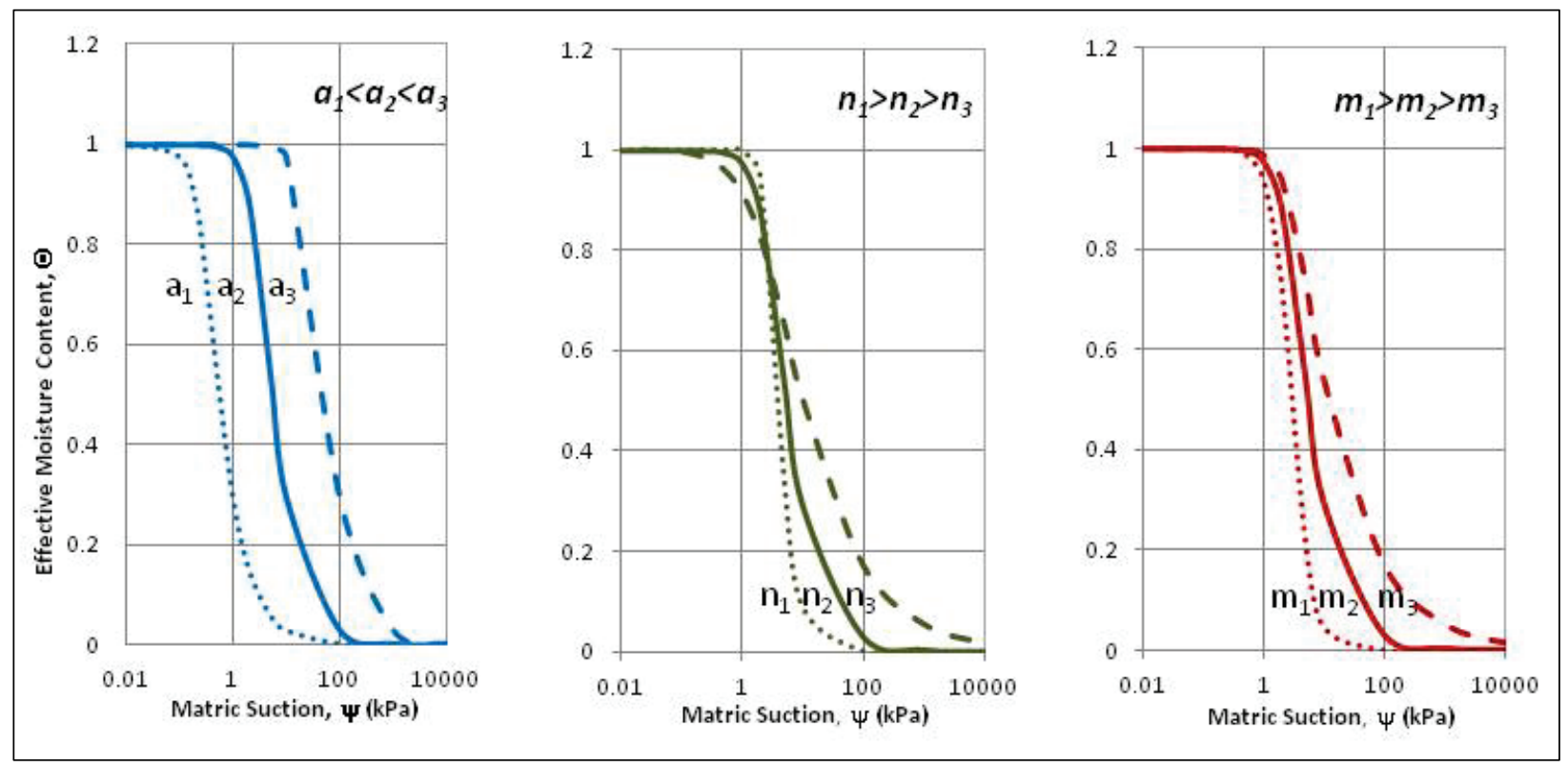

Figure 5. Effect of van Genuchten model parameters on the shape of SWCC.

Fredlund and Xing (1994)

$$
\theta=C(\psi) \frac{\theta_{s}}{\left\{\ln \left[e+\left(\frac{\psi}{a}\right)^{n}\right]\right\}^{m}}
$$

where, 


$$
C(\psi)=\left[1-\frac{\ln \left(1+\frac{\psi}{\psi_{r}}\right)}{\ln \left(1+\frac{1,000,000}{\psi_{r}}\right)}\right]
$$

$a=\psi_{\mathrm{i}}$, a soil parameter dependent on AEV

$$
\begin{gathered}
m=3.67 \ln \left(\frac{\theta_{s}}{\theta_{i}}\right) \\
\mathrm{n}=\frac{1.31^{m+1}}{m \theta_{i}} 3.72 s \psi_{i}
\end{gathered}
$$

where,

$$
\begin{aligned}
\psi_{i}= & \text { the matric suction dependent on the water content and occurring at the } \\
& \text { inflection point of the SWCC which is slightly greater than the AEV }(\mathrm{kPa}) \\
\psi_{r}= & \text { the matric suction representing the residual water content, and } \\
s= & \text { the slope of the line tangent to the function that passes through the } \\
& \text { inflection point. }
\end{aligned}
$$

The parameters $a, n$, and $m$ are illustrated in Figure 6 .

$$
\Theta=\frac{1}{\left[1+\left(\frac{\psi}{a}\right)^{n}\right]^{m}}
$$

The correction factor $C(\psi)$ allows a progressive decrease in water content at high matric suction values, forcing the value of $\theta$ to zero at $\psi$ value of $1 \times 10^{6} \mathrm{kPa}$. This value is supported by thermodynamic considerations.

The previous four models are used in the seepage analysis program SLIDE (RocScience 2011). SEEP/W (Geo-Slope 2012) incorporates the two more recent ones: van Genuchten (1980) and Fredlund and Xing (1994). If data points are known on the SWCC, SEEP/W has an algorithm that fits the Fredlund and Xing equation and estimates the values of $a, n$, and $m$. 


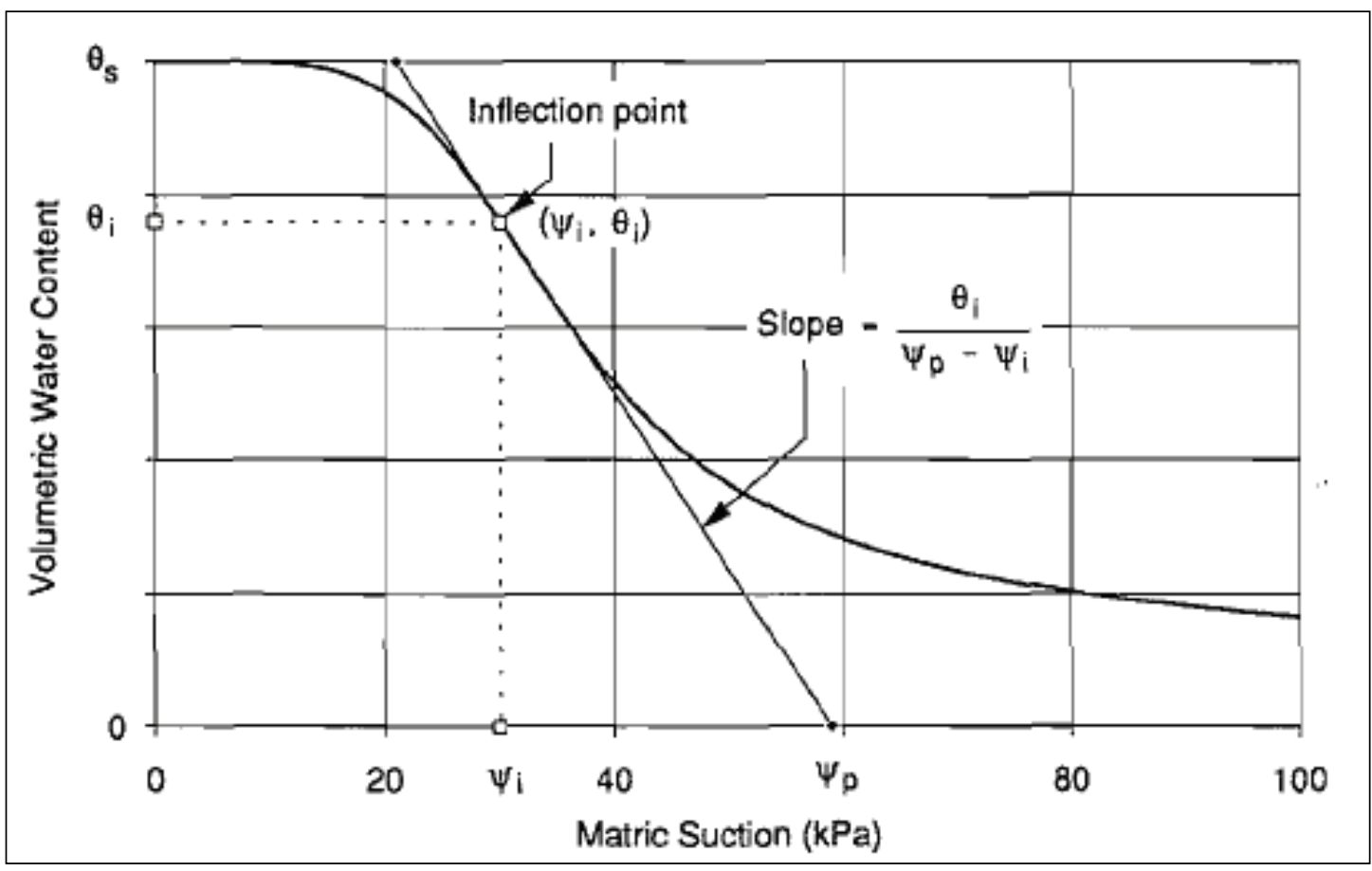

Figure 6. A sample plot for the graphical solution of the three parameters $(a, n$, and $m)$ (Fredlund et al. 1994).

Leong and Rahardjo (1997) compared 30 equations for the SWCC. They noted that most of these equations are empirical in nature and were suggested based on the shape of the SWCC as measured. The models that present a sigmoid or S-shaped function are more versatile and give a better fit to the SWCC. When comparing the minimum sum squared residual value obtained from the best fit of each equation, they noted that the equations that have four parameters (for example, van Genuchten 1980 and Fredlund and Xing 1994) performed much better than the equations with three parameters (for example, Gardner 1958, Brooks and Corey 1964) and that Fredlund and Xing equation performed marginally better than van Genuchten.

PREDICTIVE MODELS: The predictive models for the SWCC as previously described can be grouped into four general approaches. The first two approaches can be best used in practice, because they correlate the SWCC estimates to soil index properties typically available for geotechnical projects. The first approach correlates soil index properties directly to SWCC prediction, and the second approach correlates soil index properties using multiple regressions to the parameters of already given mathematical models. Sleep (2011) provides a comprehensive review of such models.

To estimate the SWCC for transient seepage analyses, SEEP/W uses two closed-form models: van Genuchten (1980) and Fredlund and Xing (1994). In addition, SEEP/W incorporates the Modified Kovacs (MK) predictive model (Aubertin et al. 2003), which uses basic index soil properties to estimate the SWCC. SEEP/W provides a list of sample SWCCs for six different soils (Figure 3,) but the user's manual states that they should be used for initial checking only. The SEEP/W user is able to insert add-in functions or input the SWCC as discrete coordinates based on available methods that estimate the curves based on grain-size information, soil type, or published data. 
A spreadsheet has been developed to compare the four mathematical models that were discussed given that the input parameters are known. The spreadsheet also compares seven different predictive models and provides an estimate of the parameters required by SEEP/W to use either Fredlund and Xing (1994) or van Genuchten (1980) equations in unsaturated soils modeling. These seven models are selected as an example of fitting data to mathematical equations using different approaches. Some assumptions have been made in the calculations contained in the spreadsheet when some of the constants or the parameters are not clearly determined in the respective methods. An additional feature is to generate a text file that contains the SWCC data points, which can easily be pasted into SEEP/W.

As with any other estimates of engineering properties of soils, predictive equations have their limitations and should be calibrated or verified using measurements on the modeled material. Appendix A includes screen captures of the spreadsheet introduction and output for fine-grained soils and coarse-grained soils. A brief description of the seven models is presented in the following paragraphs:

Model 1: Saxton et al. (1986). Saxton et al. (1986) extended the work of Rawls et al. (1982) to create an equation for a continuous SWCC based on the regression coefficients developed by Rawls et al. Saxton et al. used the general fit of the Brooks and Corey (1964) equation for the SWCC.

$$
\psi=A \Theta^{B}
$$

where, $A=\psi_{e} \theta_{s}^{-B}, \psi_{e}$ is the soil suction at the $\mathrm{AEV}(\mathrm{kPa})$, and $\mathrm{B}$ is a curve-fitting constant. They divided the SWCC into three segments: from saturation to the AEV, AEV to $10 \mathrm{kPa}$, and greater than $10 \mathrm{kPa}$. The first segment is a constant value, equal to $\theta_{s}$, then a straight line along the second segment. For the last segment, they proposed expressions for A and B correlated to the percent of clay $(\leq 0.002 \mathrm{~mm})$ and percent sand $(<2 \mathrm{~mm})$ in the soil being modeled. It is noted that $2 \mathrm{~mm}$ is the sand size corresponding to "medium sand" according to the Unified Soil Classification System (USCS). Saxton et al. found the proposed equation to be satisfactory when compared to measured SWCC, except for soils with clay contents above 60 percent or below 10 percent.

Model 2: Zapata et al. (2000). Zapata et al. (2000) proposed a model to determine the SWCC based on soil index properties. They used a database of 190 soils consisting of 70 plastic soils and 120 non-plastic soils. They used multiple regressions and the Fredlund and Xing (1994) equation.

As shown in Figure 7, with the correlation equations developed, an infinite number of SWCCs can be generated using $w \cdot P I$ for plastic soils, where $w$ is the percent passing the \#200 sieve, and $P I$ is the plastic index, and using $D_{60}$ for non-plastic soils. The data from their study and examination of several other SWCCs show clearly that the SWCC moves to the right with increasing plasticity. The correlations and algorithms developed from their study provide a smooth transition across the spectrum of soils.

Zapata et al. (2000a) concluded that SWCC can probably be estimated from $D_{60}$ or $w \cdot P I$ about as accurately as it can be measured, unless the laboratory or person making the measurement is highly experienced. And, it is difficult to develop a predictive model for SWCCs that is consistent with all of the SWCCs reported in the literature because of the fairly high probability that 
any given measured SWCC has significant experimental error associated with it. In their paper they stated that, if a single laboratory is asked to reproduce the SWCC for a single soil, the variability can typically be as great as the difference between the $w \cdot P I=10$ curve and the $w \cdot P I=$ 30 curve shown in Figure 7.

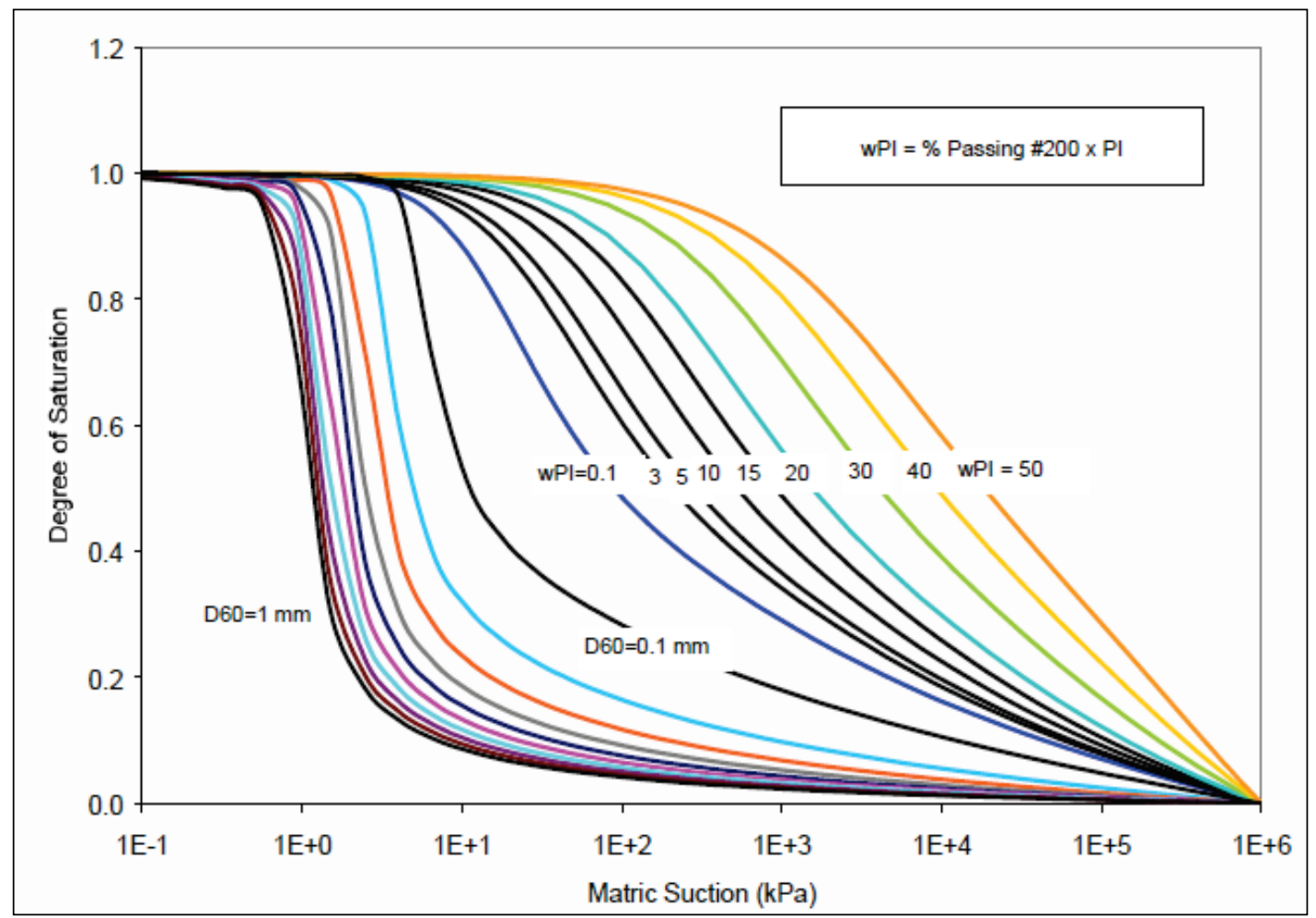

Figure 7. Predicted SWCC based on $D_{60}$ and w.PI (Zapata et al. 2000b).

The Enhanced Integrated Climatic Model (EICM), developed for the Federal Highway Administration (FHWA), was designed to simulate the behavior of pavement and subgrade materials over several years of operation. The study by Zapata et al. (2000b) was used in modifying EICM (ver. 2.6) to improve the predictions of the moisture content of unbound materials. The modifications included the addition of a better functional fit for the soil SWCC, the incorporation of an algorithm capable of predicting the SWCC based on soil index properties, and the prediction of the unsaturated hydraulic conductivity based on the SWCC, and the development of sets of default soil parameters based on the American Association of State Highway and Transportation Officials (ASSHTO) Soil Classification System.

Model 3: Aubertin et al. (2003). Aubertin et al. presented a method to predict the SWCC based on modifications to the method proposed by Kovacs (1981). The modifications were made to Kovac's method to better represent materials that were not covered in the original method, such as tailings from hard-rock mines and clay soils. The model is developed by defining the degree of saturation for two main components:

1. The amount of water stored in a soil by capillary forces that exist at relatively small negative pore-water pressures. This component is associated more with coarse grained materials. 
2. The volumetric water content at large negative pore-water pressures where the amount of water that exists in the soil is primarily a function of adhesion. This component is associated more with fine-grained materials.

Both of these components can be evaluated from material property information, such as particle size, the shape of the particles and the porosity. The Aubertin et al. MK model uses the Fredlund and Xing (1994) correction factor $C(\psi)$.

Model 4: Perera et al. (2005). Perera et al. (2005) extended the work of Zapata et al. (2000b) and used multiple regression and the Fredlund and Xing (1994) equation with a database of 154 non-plastic and 63 plastic soils to derive equations for the SWCC based on the grain-size distribution for coarse-grained soils, and the plasticity index for fine-grained or plastic soils.

Model 5: Ghanberian et al. (2010). Ghanberian et al. (2010) developed a model that determines parameter $m$ in the van Genuchten equation to describe the SWCC of unsaturated soils. They used a previously developed approach to estimate parameter $m$ from the pore size distribution index $(\lambda)$ of the Brooks and Corey (1964) model incorporating a relationship between $\lambda$ and the fractal dimension, D, of the SWCC. The fractal dimension is a statistical index on how accurate the estimated model matches the measured points. Ghanberian et al. used two data sets containing 75 samples from the unsaturated soil hydraulic database (UNSODA) and 72 samples from literature to evaluate the approach. They concluded that the fractal approach performed better than the Rosetta model. Table 1 provides typical values that can be used as an estimate for van Genuchten model.

\section{Table 1. Default initial estimates of selected parameters in models for unsaturated hydraulic functions (UNSODA manual after Carsel and Parrish 1988).}

\begin{tabular}{|l|c|c|c|c|c||}
\multicolumn{1}{c|}{ Soil Type } & $\theta_{r}$ & $\theta_{s}$ & $n$ & $\begin{array}{c}\boldsymbol{a} \\
\text { (kPa) }\end{array}$ & $\begin{array}{c}\text { Ks } \\
\text { (cm/sec) }\end{array}$ \\
\hline \hline Sand & 0.045 & 0.43 & 2.68 & 0.677 & $8.25 \mathrm{E}-03$ \\
\hline Loamy sand & 0.057 & 0.41 & 2.28 & 0.791 & $4.05 \mathrm{E}-03$ \\
\hline Sandy loam & 0.065 & 0.41 & 1.89 & 1.308 & $1.22 \mathrm{E}-03$ \\
\hline Sandy clay loam & 0.100 & 0.39 & 1.48 & 1.663 & $3.64 \mathrm{E}-04$ \\
\hline Loam & 0.078 & 0.43 & 1.56 & 2.725 & $2.89 \mathrm{E}-04$ \\
\hline Silt loam & 0.067 & 0.45 & 1.41 & 4.905 & $1.25 \mathrm{E}-04$ \\
\hline Clay loam & 0.095 & 0.41 & 1.31 & 5.163 & $7.22 \mathrm{E}-05$ \\
\hline Silt & 0.034 & 0.46 & 1.37 & 6.131 & $6.94 \mathrm{E}-05$ \\
\hline Clay & 0.068 & 0.38 & 1.09 & 12.263 & $5.55 \mathrm{E}-05$ \\
\hline Sandy clay & 0.100 & 0.38 & 1.23 & 3.633 & $3.33 \mathrm{E}-05$ \\
\hline Silty clay loam & 0.089 & 0.43 & 1.23 & 9.810 & $1.94 \mathrm{E}-05$ \\
\hline Silty clay & 0.070 & 0.36 & 1.09 & 19.620 & $5.55 \mathrm{E}-06$ \\
\hline
\end{tabular}

$m=1-1 / n$

$\theta_{s}$ is the saturated volumetric water content which is equal to porosity

Model 6: Sleep (2011). Sleep developed SWCC charts by querying laboratory drying tests based on four soil groups categorized according to saturated hydraulic conductivity: $>10^{-1} \mathrm{~cm} / \mathrm{sec}$ (coarse sand), $10^{-1}-10^{-3} \mathrm{~cm} / \mathrm{sec}$ (fine sand), $10^{-3}-10^{-5} \mathrm{~cm} / \mathrm{sec}$ (silty sand), and $10^{-5}-10^{-7} \mathrm{~cm} / \mathrm{sec}$ 
(silt). The data queried contained volumetric moisture content versus soil suction. The data points were plotted on semi-log plots. Best fit lines for the drying curve data were developed. The wetting curves were constructed based on the finding by Yang et al. (2004), that the hysteresis between the wetting and drying SWCC is variable but is approximately one order of magnitude. The 90 percent confidence limit was constructed using 1.28 times the standard deviation of the data set. Figure 8 is an example of the developed charts for fine sand.

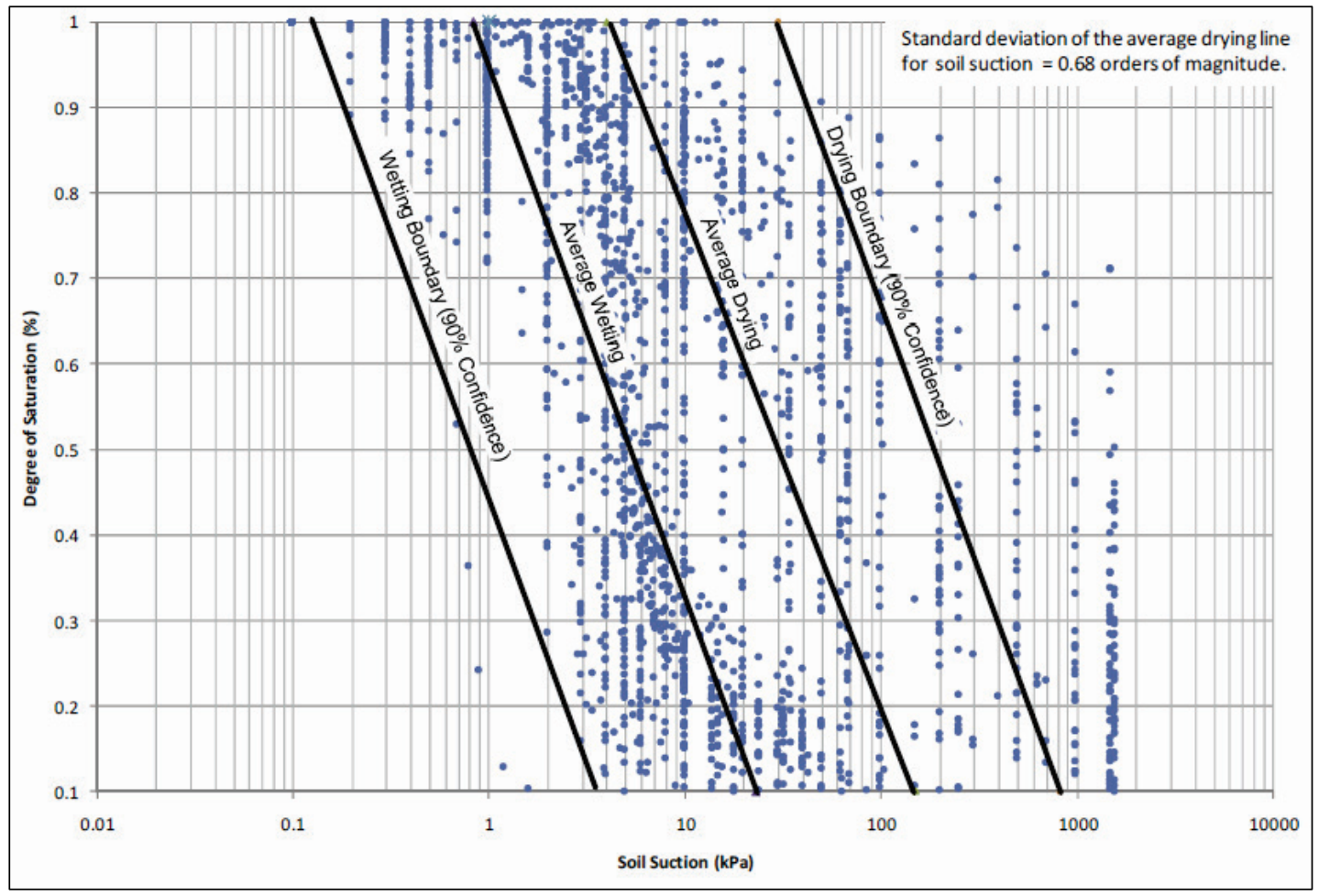

Figure 8. SWCC for fine sand $\left(\mathrm{k}=10^{-1}\right.$ to $\left.10^{-3} \mathrm{~cm} / \mathrm{sec}\right)$ constructed from the UNSODA database (Sleep 2011).

Sleep (2011) noted that it is not conclusive that one of the proposed fitting methods is significantly more accurate than the others, and that it appears unlikely that the soil properties required for transient seepage analyses can be estimated with a high degree of accuracy, no matter how sophisticated the fitting relationships that are used.

Model 7: Benson et al. (2014). Benson et al. (2014) studied the effect of median particle size and uniformity of particle sizes (well-graded vs. poorly-graded) in clean sands on the SWCC and the van Genuchten parameters $a$ and $n$. For the drying SWCC of uniform sands, as the particles become finer, the air entry suction increases ( $a$ increases), and the slope diminishes slightly ( $n$ decreases). Increasing the range of particle sizes, quantified by an increased coefficient of uniformity $\left(C_{u}=D_{60} / D_{10}\right)$, also increases the air entry suction (higher $a$ ) and reduces the slope (lower $n$ ) of the SWCC. Benson et al. concluded that the range of particle sizes has a larger effect on the slope and $n$ of the SWCC, and median particle size has a larger effect on the air entry suction and $a$. Similar effects occur for the wetting SWCC, although the impact on the water entry suction is less than the impact on the air entry suction (the water entry suction is shown on Figure 2). Figure 9 shows a conceptual illustration of the above findings. 


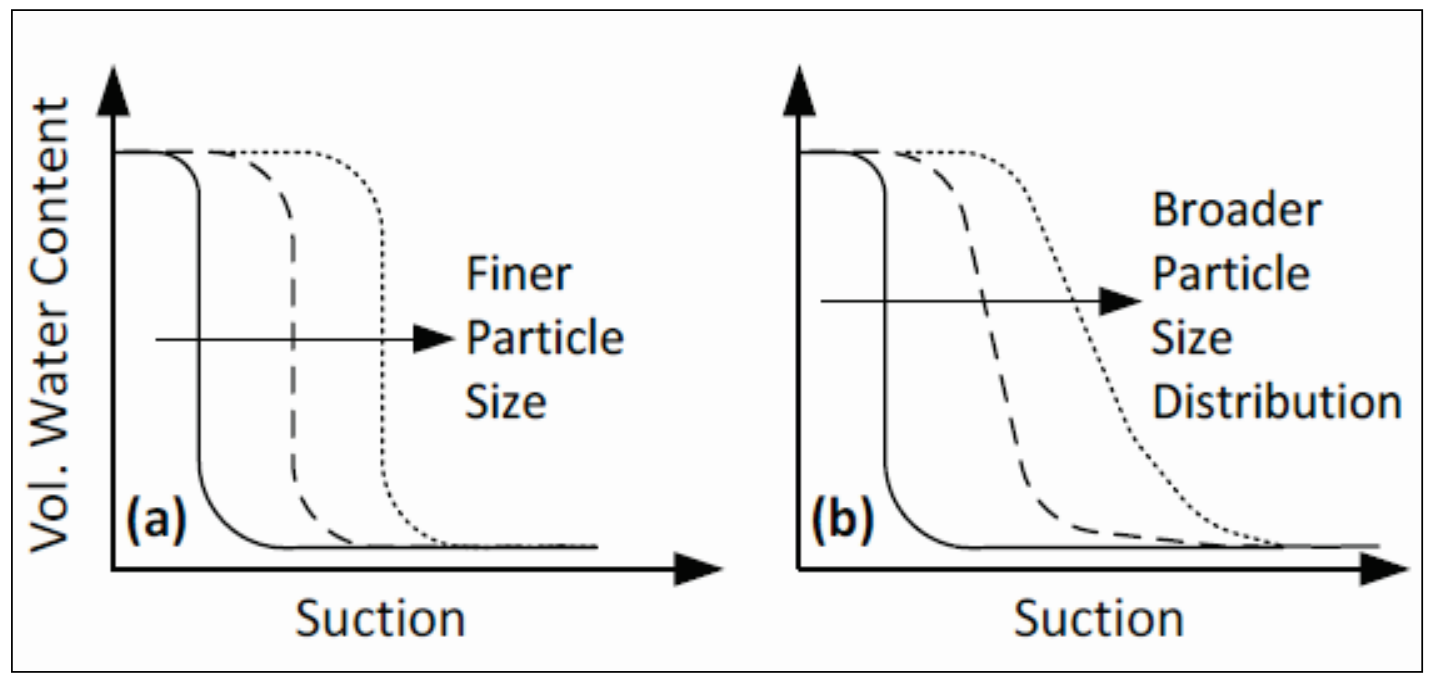

Figure 9. Conceptual diagram of effect of (a) median particle size of uniform sand, and (b) range of particle sizes, on shape of the SWCC of sand (Benson et al. 2014).

\section{REFERENCES}

Arya, L. M., and J. F. Paris. 1981. A physioempherical model to predict the soil-moisture from particle-size distribution and bulk density data. Soil Science of America 45: 1023-1030.

Aubertin, M., M. Mbonimpaa, B. Bussièreb, and R. Chapuisa. 2003. A physically-based model to predict the water retention curve from basic geotechnical properties. Canadian Geotechnical Journal 40: 1104-1122.

Benson, C., I. Chiang, T. Chalermyanont, and A. Sawangsuriya. 2014. Estimating van Genuchten parameters $\alpha$ and $n$ for clean sands from particle size distribution data. In Soil behavior fundamentals to innovations in geotechnical engineering: 410-427.

Brooks, R. H., and A. T. Corey. 1964. Hydraulic properties of porous media. Hydrol. Pap. 3. Colo. State Univ., Fort Collins, CO, $27 \mathrm{pp}$.

Buckingham, E. 1907. Studies on the movement of soil moisture. USDA Bureau of Soils, Bulletin 38.

Carsel, R. F., and R. S. Parrish. 1988. Developing joint probability distributions of soil water retention characteristics. Water Resources Research. 24 (No. 5): 755-769.

Chin, K.-B., E.-C. Leong, and H. Rahardjo. 2010. A simplified method to estimate the soil-water characteristic curve. Canadian Geotechnical Journal, 47, 1382-1400.

Farrel, D. A., and W. E. Larson. 1972. Modelling the pore structure of porous media. Water Resour. Res., 3, 699-706.

Fredlund, D. G., and A. Xing. 1994. Equations for the soil-water characteristic curve. Canadian Geotechnical Journal 31:521-532.

Fredlund, D. G., and S. L. Houston. 2001. Discussion Session 1.3, Laboratory techniques for unsaturated soils. In Proceedings of the 15th International Conference on Soil Mechanics and Geotechnical Engineering, 4: 2913-2914, Aug. 27-31, Istanbul, Turkey. 
Fredlund, M. D., G. W. Wilson, and D. G. Fredlund. 2002. Use of grain-size distribution for estimation of the soilwater characteristic curve. Canadina Geotech. J., 39:1103-1117.

Gardner, W. R. 1958. Some steady state solutions of unsaturated moisture flow equations with applications to evaporation from a water table. Soil Sci. 85(4):228-232.

Ghanbarian, A. B., A. Liaghat, G. H. Huang, and M. Th. van Genuchten. 2010. Estimation of the van Genuchten soil water retention properties from soil textural data. Soil Science Society of China 20(4):465-465. Elsevier.

Geo-Slope. 2012. Seepage modeling with SEEP/W, an engineering methodology. Calgary, Alberta, Canada.

Gupta, C. S., and W. E. Larson. 1979. Estimating soil water retention characteristics from particle size distribution, organic matter percent, and bulk density. Water Resources Management 15(6).

Headquarters, U.S. Corps of Engineers. 1993. Seepage analysis and control for dams. Engineer Manual 1110-21901. Washington, D.C.: Headquarters, U.S. Army Corps of Engineers.

Houston, W. N., H. B. Dye, C. E. Zapata, Y. Y. Perera, and A. Harraz. 2006. Determination of SWCC using one point suction measurement and standard curves. In 4th International Conference on Unsaturated Soils, April 2, 2006 - April 5, 2006, Carefree, AZ, United States, 1482-1493.

Johari, A., G. Habibagahi, and A. Ghahramani. 2006. Prediction of soil-water characteristic curve using genetic programming. Journal of Geotechnical and Geoenvironmental Engineering 132(5):661-665.

Kovacs, G. 1981. Seepage hydraulics. Elsevier Science Publishers, Amsterdam.

Leong, E. C., and H. Rahardjo. 1997. Review of soil-water characteristic curve equations. Journal of Geotechnical and Geoenvironmental Engineering 123(12).

Pachepsky, Y. A., D. Timlin, and G. Varallyay. 1996. Artificial neural networks to estimate soil water retention from easily measurable data. Soil Sci. Soc. Am.J. 60(3): 727-733.

Perera, Y. Y., C. E. Zapata, W. N. Houston, and S. L. Houston. 2005. Prediction of the soil-water characteristic curve based on grain-size-distribution and index properties. ASCE Geotechnical Special Publication 130, Reston, VA, 49-60.

Rawls, W. J., D. L. Brakensiek, and K. E. Saxton. 1982. Estimation of soil water properties. Transactions of the ASAE, 25(5): 1316-1320.

RocScience. 2011. SLIDE 6.0, 2D limit equilibrium slope stability analysis. Toronto, Ontario, Canada.

Saxton, K. E., W. J. Rauls, J. S. Romberger, and R. I. Papendick. 1986. Estimating generalized soil-water characteristics from texture. Soil Science Society of America Journal 50(4):1031-1036.

Sleep, M. D. 2011. Analysis of transient seepage through levees. PhD diss. Virginia Polytechnic Institute and State University, Blacksburg, VA.

Tracy, F. T., T. W. Brandon, and M. K. Corcoran. 2016. Transient seepage analyses in levee engineering practice. ERDC TR-16-8. Vicksburg, MS: U.S. Army Engineer Research and Development Center.

van Genuchten, M. Th. 1980. A closed-form equation for predicting the hydraulic conductivity of unsaturated soils. Soil Science of America 44:892-898.

Williams, L., R. E. Prebble, W. T. Williams, and C. T. Hignett. 1983. The influence of texture, structure and clay mineralogy on the soil moisture characteristics. Australian J. of Soil Res. 21:15-32. 
Yang, H., H. Rahardjo, E.-C. Leong, and D. G. Fredlund. 2004. Factors affecting drying and wetting soil-water characteristic curves of sandy soils. Canadian Geotechnical Journal 41(5):908-920.

Zapata, C. E., W. N. Houston, S. L. Houston, and K. D. Walsh. 2000a. Soil-water characteristic curve variability. ASCE Geotechnical Special Publication 99, Denver, CO, 84-124.

Zapata, C. E., M. W. Witczak, W. N. Houston, C. Richter, G. Larson, and K. D. Walsh. 2000b. Appendix DD-4: Improvement of the integrated climatic model for moisture content predictions. Guide for mechanisticempirical design of new and rehabilitated pavement structures. TRB-NCHRP.

NOTE: The contents of this technical note are not to be used for advertising, publication, or promotional purposes. Citation of trade names does not constitute an official endorsement or approval of the use of such products. 